\title{
Influence of Isoflurane Concentration and Hypoxia on Functional Magnetic Resonance Imaging for the Detection of Bicuculline-Induced Neuronal Activation
}

\author{
Masahiro Abo a Masahiko Suzuki ${ }^{b}$ Atushi Senoo ${ }^{c}$ Satoshi Miyano ${ }^{a}$ \\ Hideki Yamauchi $^{a}$ Kyozo Yonemoto $^{c}$ Shu Watanabe ${ }^{c}$ Lars Edström $^{d}$ \\ Departments of a Rehabilitation Medicine and ${ }^{\mathrm{b}}$ Neurology, Jikei University School of Medicine, Tokyo, Japan; \\ cTokyo Metropolitan University of Health Science, Tokyo, Japan, and dDepartment of Clinical Neuroscience, \\ Karolinska Hospital, Stockholm, Sweden
}

\section{Key Words}

Functional MRI · Cerebral blood volume · Intravascular contrast agent $\cdot$ Bicuculline $\cdot$ Pharmacological stimulation · Hypoxia - Epileptic seizures

\begin{abstract}
Our present study shows that transient changes in relative cerebral blood volume ( $\mathrm{rCBV}$ ) induced by stimulation with bicuculline under six different conditions of anesthesia can be detected with high spatial resolution functional magnetic resonance imaging (fMRI). Bicuculline was administered at a low dose to induce neural activation, and no seizure activity was noted. Of the six conditions, the maximal reaction to bicuculline was observed under $1.5 \%$ isoflurane in $60 \%$ nitrogen and $40 \%$ oxygen. Our results imply that the rCBV changes under this level of isoflurane anesthesia with body temperature maintained at $37.5^{\circ} \mathrm{C}$ are probably suitable for further fMRI studies.
\end{abstract}

Copyright $\odot 2004$ S. Karger AG, Basel

\section{Introduction}

Functional magnetic resonance imaging (fMRI) is becoming a routinely used research tool for studying human brain function and has been even applied as a diagnostic procedure in mapping brain function prior to elective neurosurgery [1]. However, in experimental animal research, the technique is still under development and has been more difficult to develop due to the interference of anesthesia with neurophysiological function.

Using fMRI to monitor neuronal activity is an indirect method that is sensitive to changes in metabolic rate and physiological properties of the tissues. Several methods to detect these metabolic changes have been described, including the BOLD technique [2], which mainly detects the different paramagnetic properties between oxy- and de-oxygenated hemoglobin, arterial spin tagging, which is sensitive to perfusion [3], and the method we have chosen, which is sensitive to blood volume changes [4]. This is achieved by administration of super paramagnetic ironoxide nanoparticles as a blood pool contrast. Mandeville et al. [5] have used the nanoparticles method to demonstrate local cerebral blood volume (CBV) changes caused by hypoxia.

\begin{tabular}{ll}
\hline KARGER & ( 2004 S. Karger AG, Basel \\
1424-862X/04/0133-0144\$21.00/0 \\
$\begin{array}{l}\text { Fax +4161306 12 34 } \\
\text { E-Mail karger@karger.ch } \\
\text { www.karger.com }\end{array}$ & $\begin{array}{l}\text { Accessible online at: } \\
\text { www.karger.com/nsg }\end{array}$
\end{tabular}

Masahiro Abo, MD, PhD

Department of Rehabilitation Medicine

Jikei University School of Medicine, 3-25-8, Nishi-Shimbashi

Minato-ku, Tokyo 105-8461 (Japan)

Tel. +8133433 1111, Fax +81 35497 4120, E-Mail abo@jikei.ac.jp 
Regardless of the method selected, the basic important parameters are the neurophysiological function and the stimulus. We have used different physiological conditions and induced neuronal activation by systemic administration of bicuculline, a competitive $\gamma$-aminobutyric acid $\left(\mathrm{GABA}_{\mathrm{A}}\right)$ receptor antagonist [6]. This antagonist blocks many physiologic functions controlled by the inhibitory neurotransmitter $\mathrm{GABA}_{\mathrm{A}}$ in the brain and when administered at a high dose it can induce epileptic activity. Epileptic seizures induced by high-dose bicuculline occur secondary to increased cerebral blood flow (CBF), which reaches a maximum of 9 times higher than the control value, 15-30 s after the injection [7]. The bicucullineinduced increase in CBF is influenced by an increase in brain adenosine level [8], increase in brain cyclic AMP level irrespective of the adenosine level [9], and increase in systemic blood pressure, $\mathrm{K}^{+}$and $\mathrm{H}^{+}$activities [10] during the seizure period. Meidrum and Nilsson [7] described a marked rise in mean arterial blood pressure and a dramatic fall in cerebrovascular resistance following bicuculline injection. Bicuculline also induces tachycardia, hypertension and sympathetic nerve activity [11]. Other studies investigating the neural responses to bicuculline showed a high amplitude spiked discharge on the electroencephalogram (EEG), which accompanied the increase in arterial blood pressure [7-11]. Interestingly, the EEG changes were less marked when bicuculline was injected before, during or after hypoxia $[12,13]$. Additional hypoxia, secondary to neurogenic pulmonary edema [14], is a common complication of seizures leading to further deterioration of neuronal function. Bioenergetic failure elicited by the complicating hypoxia also leads to aggravation or precipitation of brain cell damage [12, $15]$.

In the present study, we administered bicuculline at a low dose to induce neuronal activation without any signs of seizures. Our experimental design was based on the assumption that the level of anesthesia and body temperature would affect the fMRI signal due to changes in local blood volume in the brain. Using this strategy, we evaluated the alteration of the fMRI signal intensity before, during and after bicuculline stimulation under different conditions of anesthesia.

\section{Methods}

Animal Model and Experimental Design

This study was performed according to the animal care legislation and was approved by the animal experimentation ethics committees of our institutions. Male Sprague-Dawley rats $(\mathrm{n}=16)$ weighing 200-
$230 \mathrm{~g}$ (BK Universal, Stockholm, Sweden) were used. The rats were kept under standardized conditions (lights on 6 a.m. to 6 p.m., with free access to food and water). All rats were anesthetized with isoflurane (induction $3.0 \%$ in air, maintenance $1.5 \%$ in air). For the MRI experiments, the rats were anesthetized with isoflurane (1.5\%) in air. Body temperature, measured with a rectal thermometer, was maintained at $37.5^{\circ} \mathrm{C}$ with the aid of a temperature-regulated warm airstream directed at the body of the rat. For the initial experiment, we acquired an image to assess the location and position using a $\mathrm{T}_{2-}$ weighted RARE (rapid acquisition with relaxation enhancement) technique. A single slice centered at the optic chiasma and caudate putamen was taken. A single slice RARE acquisition was also carried out prior to the administration of the contrast agent. Thereafter, $600 \mu \mathrm{l}$ of Endorem (Guerbet, France) were injected intravenously. The fMRI experiment was initiated after a period of $30 \mathrm{~min}$ to allow equilibration of the contrast agent in the blood pool. Before performing fMRI studies, we changed the anesthesia conditions for $5 \mathrm{~min}$ and then continued our measurements. The conditions were as follows ( $\mathrm{n}=3$ rats per group). (1) Isoflurane $1.5 \%$ in air, (2) isoflurane $2.0 \%$ in air, (3) isoflurane 1.5 in $60 \%$ oxygen $\left(\mathrm{O}_{2}\right)$ and $40 \%$ nitrous oxide $\left(\mathrm{N}_{2} \mathrm{O}\right)$, (4) isoflurane 2.0 in $60 \% \mathrm{O}_{2}$ and $40 \% \mathrm{~N}_{2} \mathrm{O}$, (5) isoflurane 1.5 in $40 \% \mathrm{O}_{2}$ and $60 \%$ nitrogen $\left(\mathrm{N}_{2}\right)$, and (6) isoflurane 2.0 in $40 \% \mathrm{O}_{2}$ and $60 \% \mathrm{~N}_{2}$ (fig. 1). After each conditioning, we started fMRI studies. The fMRI experiment consisted of a set of 60 serial volumes. Images 6-18 were taken as baseline and bicuculline $(0.1 \mathrm{mg} / \mathrm{ml})$, dissolved in $0.1 \mathrm{M} \mathrm{HCl}$ in $0.9 \%$ saline was infused at a rate of $100 \mu \mathrm{l} / \mathrm{min}$ during capture of images $20-40$ of the total serial gradient echo images. The tail vein was cannulated using a needle syringe attached to a microinjection pump (CMA, 100, CMA Sweden), and the femoral artery was cannulated for blood pressure recording. Blood pressure was measured at $37.5^{\circ} \mathrm{C}$ by microelectrodes, before and after bicuculline injection under isoflurane 2.0 in $60 \% \mathrm{O}_{2}$ and $40 \% \mathrm{~N}_{2} \mathrm{O}$ and isoflurane 1.5 in $40 \% \mathrm{O}_{2}$ and $60 \% \mathrm{~N}_{2}(\mathrm{n}=$ 3 rats per group).

\section{MRI Imaging}

The MRI recordings were performed on a Biospec Avance 47/40 spectrometer (Bruker, Karlsruhe, Germany) with a 4.7-Tesla, $40-\mathrm{cm}$ bore diameter magnet, equipped with a $12-\mathrm{cm}$ self-shielded gradient system capable of switching $200 \mathrm{mT} / \mathrm{m}$ in $250 \mathrm{~ms}$. A RF coil $35-\mathrm{mm}$ (inner diameter) birdcage resonator was used. $\mathrm{T}_{2}$-weighted RARE experiment assessed the location and determined the position. The parameters for this experiment were $\mathrm{TR}=2,655 \mathrm{~ms}$, effective $\mathrm{TE}=$ $40.2 \mathrm{~ms}, \mathrm{FOV}=4 \mathrm{~cm}$, and matrix dimensions $=512 \times 512$. Thereafter, we measured fMRI by RARE. The imaging parameters for FSE were $\mathrm{TR}=1,135 \mathrm{~ms}$, effective $\mathrm{TE}=192 \mathrm{~ms}, \mathrm{ETL}=32$, matrix size $=$ $128 \times 64, \mathrm{FOV}=4 \mathrm{~cm}, 2$ averages, $2.0-\mathrm{mm}$ slice thickness (acquisition time $4.54 \mathrm{~s}$ per image).

\section{Data Analysis}

Image analysis was performed on one slice centered at the optic chiasma and caudate putamen. We used the FUN, which is the module for investigating fMRI using Bruker's MR acquisition and the imaging software Para Vision. The region of interest was defined on the cortex, and the change of signal intensity of the entire cortex was evaluated as the time profile.

All analyses were performed individually for each animal. The region showing a signal intensity change was selected for a temporal analysis of the relative changes in the amount of the tracer in the region according to $\Delta \mathrm{m}(\mathrm{t}) / \mathrm{m}(0)=-\ln [\mathrm{S}(t) / \mathrm{S}(0)] /\left[\mathrm{S}(0) / \mathrm{S}_{0}\right]$, where $\mathrm{S}(t)$ 
Fig. 1. Experimental design. a In the first $3 \mathrm{~min}$, the rat was set in the MRI. b, c Between minutes 3 and 40 from the start point, the animal was anesthetized with isoflurane $(1.5 \%)$ in air. At minute 15 from the start point, Endorem was injected. Before injection, we assessed the location and determined the position using MRI. We also measured the signal intensity by using fMRI parameters. d Between minutes 40 and 45 from the start point, the anesthesia condition was change. At minute 45 from the start point, we started fMRI measurement. e A total of $60 \mathrm{fMRI}$ images were made; bicuculline was injected between acquisition of images 20-40.

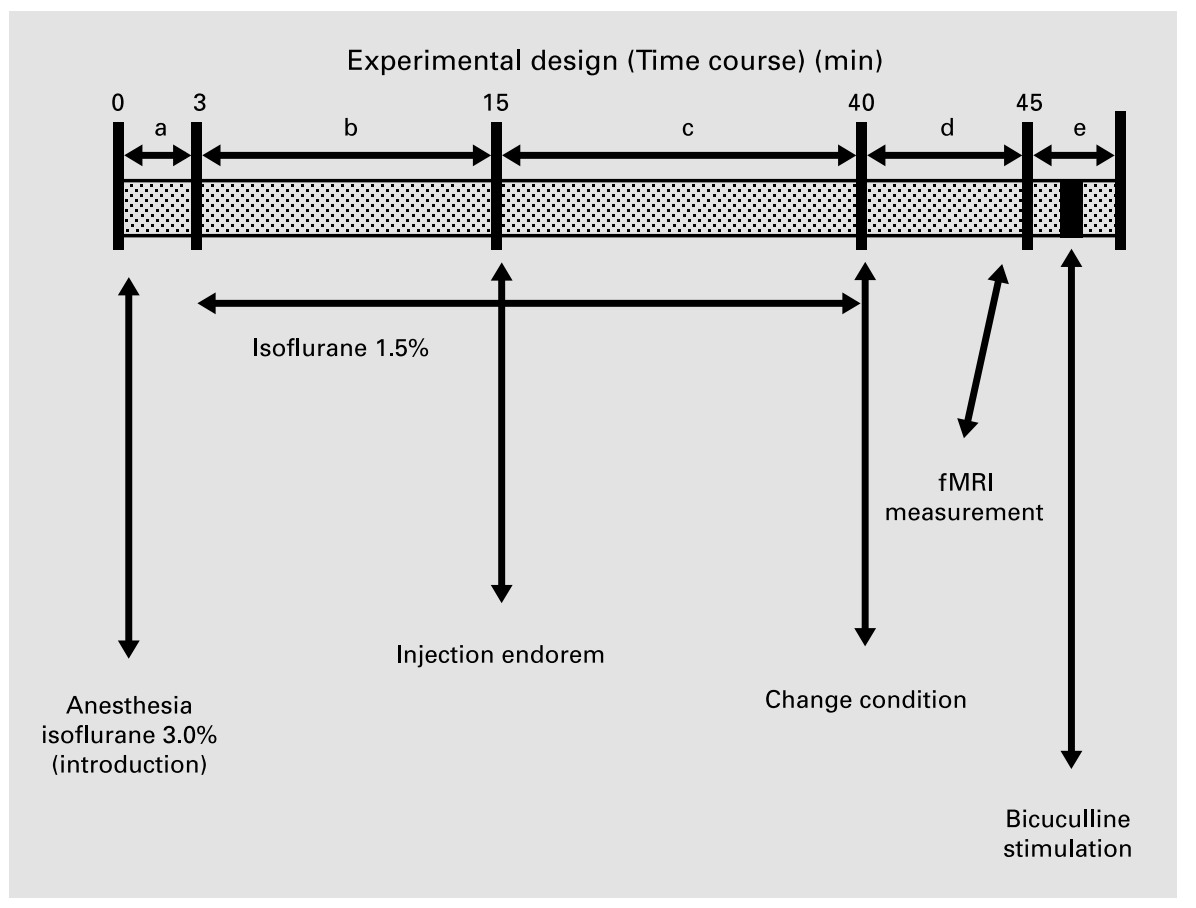

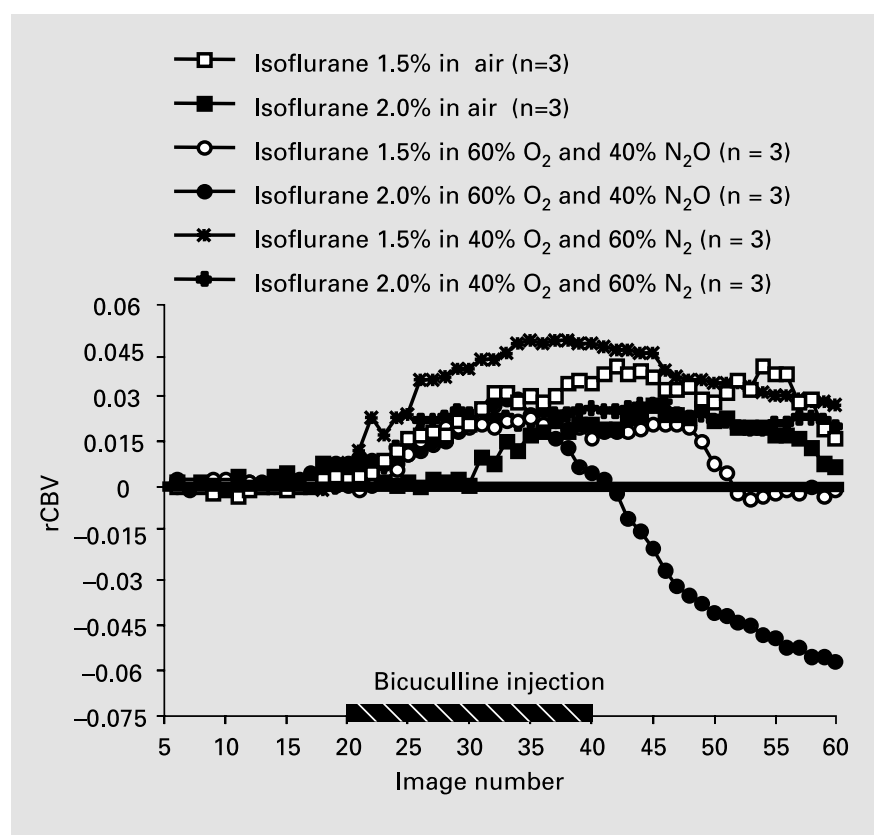

Fig. 2. Values represent the average $\mathrm{rCBV}$ at each image of the cortex measured in 3 rats under each condition. Bicuculline was injected between acquisition of images 20-40. The $\mathrm{rCBV}(t)$ was proportional to $-\ln [\mathbf{S}(t) / \mathbf{S}(0)]$, where $\mathbf{S}(t)$ is the signal intensity at time $t$, and $\mathbf{S}(0)$ represents the average signal intensity at baseline. The baseline was taken as the average signal intensity of the same rat from images 6 to 18 before bicuculline injection. represents the signal intensity at time $t, S(0)$ the average signal intensity at baseline prior to stimulation and $\mathrm{S}_{0}$ the signal intensity prior to Endorem administration. Assuming equilibrium concentration of the tracer in the blood, the ratio $\Delta \mathrm{m}(\mathrm{t}) / \mathrm{m}(\mathrm{t})$ is proportional to the change in relative blood volume, i.e., $\Delta \mathrm{CBV}(\mathrm{t}) / \mathrm{CBV}(0) \propto \Delta \mathrm{m}(\mathrm{t}) /$ $\mathrm{m}(\mathrm{t})$.

In this study, we used the baseline and the average signal intensity from images 6 to 18 before bicuculline, to evaluate the reaction to bicuculline injection. Relative CBV images were generated by computing $\Delta \mathrm{CBV}(\mathrm{t})-\ln [\mathrm{S}(\mathrm{t}) / \mathrm{S}(0)]$ on a pixel-by-pixel basis using an intensity threshold (10\% of the maximum intensity) to eliminate division by noise intensity.

\section{Results}

After a rapid drop in the signal intensity due to the first-pass effect of the contrast agent, the signal recovered within a couple of seconds to less than $50 \%$ of its initial intensity due to recirculation $(600 \mu 1$, Endorem). Almost no or very small signal recovery was observed during the short duration of the fMRI experiment. After stimulation with bicuculline, the region-specific response was opposite to the signal recovery due to elimination of the contrast agent. The average values of $\mathrm{rCBV}$ computed at each of the images, under the six different conditions of anesthesia mentioned above, are plotted in figure 2. Examination of the effects of different concentrations of isoflurane showed that the response to bicuculline injection was
Abo/Suzuki/Senoo/Miyano/Yamauchi/ Yonemoto/Watanabe/Edström 
Fig. 3. Six representative images showing spatial and temporal activation in coronal slices after bicuculline stimulation. fMRI images were prepared by comparing with images $6-18$ taken before bicuculline injection. Images show the activation patterns during the acquisition of images 4150. Red color area: increase of $\mathrm{rCBV}$; yellow color area: decrease of $\mathrm{rCBV}$.

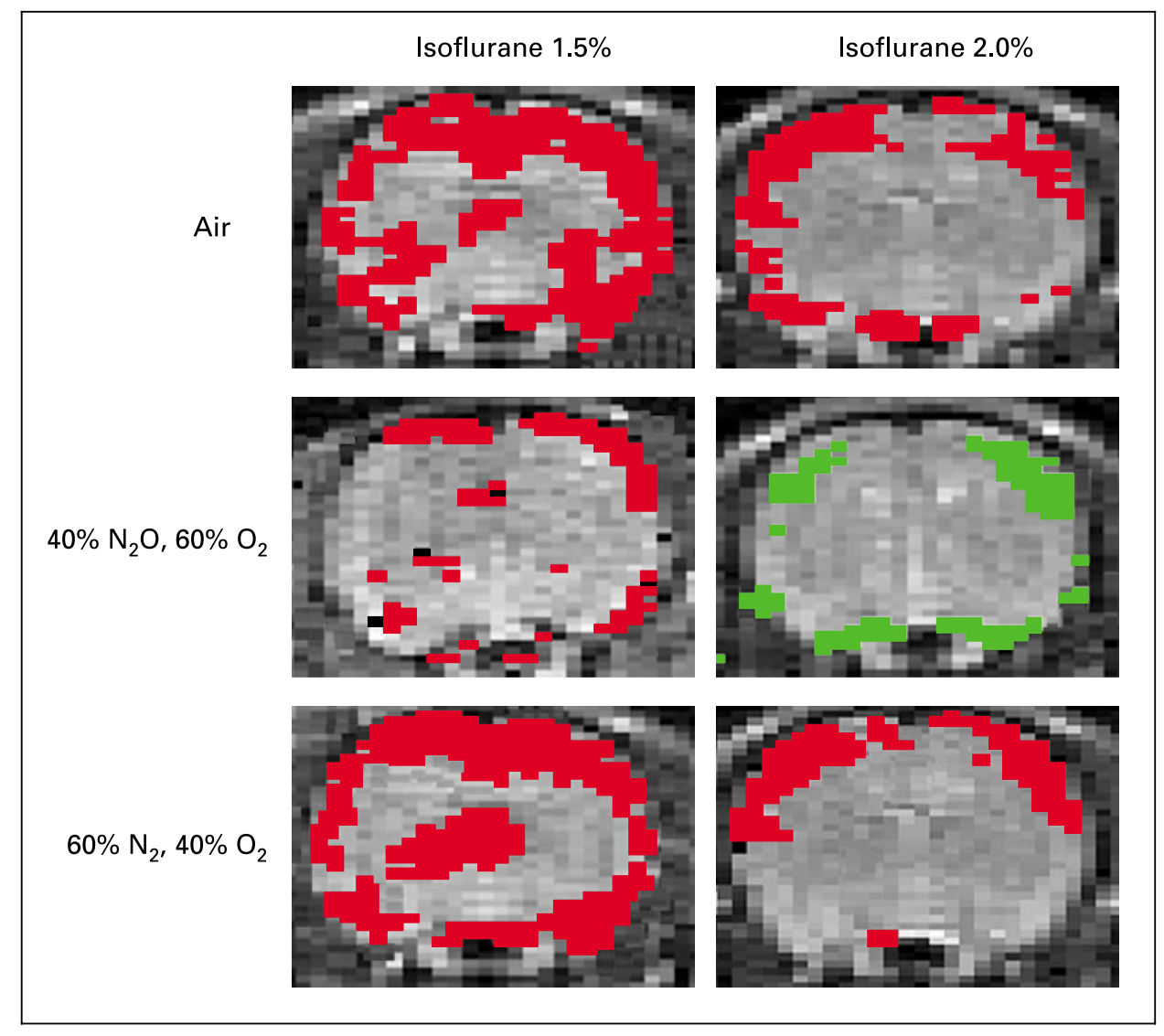

Table 1. Experimental conditions and physiological variables

\begin{tabular}{llllll}
\hline Condition & Bicuculline & No. & $\begin{array}{l}\text { BP before } \\
\text { injection }\end{array}$ & $\begin{array}{l}\text { BP after } \\
\text { injection }\end{array}$ & \% change \\
\hline A & Uninjected & a & $135 / 110$ & $133 / 112$ & $-1.5 \% / 1.8 \%$ \\
A & Injected & b & $112 / 69$ & $114 / 70$ & $1.8 \% / 1.4 \%$ \\
A & Injected & c & $100 / 88$ & $102 / 91$ & $2.0 \% / 3.4 \%$ \\
A & Injected & d & $108 / 75$ & $118 / 80$ & $9.3 \% / 6.7 \%$ \\
B & Uninjected & a & $103 / 110$ & $113 / 112$ & $-9.7 \% / 1.8 \%$ \\
B & Injected & b & $121 / 71$ & $122 / 74$ & $0.83 \% / 4.2 \%$ \\
B & Injected & c & $96 / 84$ & $96 / 79$ & $0 \% /-5.9 \%$ \\
B & Injected & d & $95 / 93$ & $99 / 97$ & $4.2 \% / 4.30 \%$ \\
\hline
\end{tabular}

Condition A: $\mathrm{N}_{2} 60 \%, \mathrm{O}_{2} 40 \%$ isoflurane $1.5 \%$.

Condition $\mathrm{B}: \mathrm{N}_{2} \mathrm{O} 40 \%, \mathrm{O}_{2} 60 \%$ isoflurane $2.0 \%$. more notable in the cortex at $1.5 \%$ isoflurane than at $2.0 \%$ isoflurane. The rCBV decreased under the combination of $2.0 \%$ isoflurane and $60 \% \mathrm{O}_{2}$ and $40 \% \mathrm{~N}_{2} \mathrm{O}$.

Table 1 summarizes the experimental conditions and changes in blood pressure. The numbers of rats were 1 control (no injection of bicuculline) and 3 bicuculline- injected rats under isoflurane 2.0 in $60 \% \mathrm{O}_{2}$ and $40 \%$ $\mathrm{N}_{2} \mathrm{O}$ and isoflurane 1.5 in $40 \% \mathrm{O}_{2}$ and $60 \% \mathrm{~N}_{2}$. The blood pressure tended to increase slightly after bicuculline injection.

Figure 3 shows the activation pattern during the acquisition of images $41-50$ after stimulation. fMRI images 
were constructed by comparing images $6-18$ before bicuculline injection. The strongest response between images 41-50 was observed under isoflurane 1.5 in $40 \% \mathrm{O}_{2}$ and $60 \% \mathrm{~N}_{2}$. With $2.0 \%$ isoflurane and $60 \% \mathrm{O}_{2}$ and $40 \% \mathrm{~N}_{2} \mathrm{O}$, the signal intensity from images 41 to 50 showed strong movement to the opposite direction indicating vasoconstriction.

\section{Discussion}

The unique aspect of this study was that bicuculline was administered at a low dose. The dose used here was exceedingly low compared with previous reports that used 14 times the dose used in our study $[7,12]$. The low dose of bicuculline used in our study did not cause a significant rise in arterial blood pressure reported in previous studies [7-11]. Furthermore, we were able to measure definite changes in rCBV under different conditions, which had not been reported previously.

fMRI has been applied to study focal brain activation in rats induced by intravenous administration of bicuculline [4]. In our study, we also found bicuculline-related changes in $\mathrm{rCBV}$ in the cortex. However, the use of a higher concentration of isoflurane (i.e., from 1.5 to $2.0 \%$ ) reduced the magnitude of bicuculline-induced rCBV response in the cortex as assessed by the rate of signal intensity change. Volatile general anesthetics depress neuronal activity in the mammalian central nervous system and enhance inhibitory $\mathrm{Cl}^{-}$currents flowing across the GA$\mathrm{BA}_{\mathrm{A}}$ receptor-ion channel complex. This is because such anesthetics increase overall $\mathrm{GABA}_{\mathrm{A}}$-mediated synaptic inhibition and decrease spontaneous action potential firing [16]. Thus, with increasing the concentration of isoflurane, the magnitude of overall $\mathrm{GABA}_{\mathrm{A}}$-mediated synaptic inhibition also increases, which can also decrease in response to bicuculline injection.

Previous studies concluded that induction of hypoxia before and after bicuculline injection extended the total reaction and decreased seizure activity because of cell membrane depolarization $[15,17]$ and metabolic decompensation $[12,15,18,19]$. In other words, hypoxia might lead to suppression of autoregulation, with subsequent reduction in blood pressure accompanied by a decrease in $\mathrm{CBF}$. In our study, the rCBV initially increased under $2.0 \%$ isoflurane in $60 \% \mathrm{O}_{2}$ and $40 \% \mathrm{~N}_{2} \mathrm{O}$ but then decreased precipitously (fig. 2). However, under this anesthetic condition, the blood gases before and after bicuculline did not manifest arterial hypoxemia, and the blood pressure only increased slightly. Although the mechanism underlying this phenomenon is not clear, several factors, including high concentration of isoflurane, may have contributed to the deleterious effect of $\mathrm{N}_{2} \mathrm{O}$. It was previously demonstrated that $\mathrm{N}_{2} \mathrm{O}$ might play a crucial role in the process of calpain activation and markedly reduced the protective effect of isoflurane during anesthetic management [20]. Pelligrino et al. [21] pointed out that exposure to $\mathrm{N}_{2} \mathrm{O}$ was associated with an increase in cerebral metabolic rate for $\mathrm{O}_{2}$. The combination of $2.0 \%$ isoflurane and $60 \% \mathrm{O}_{2}-40 \% \mathrm{~N}_{2} \mathrm{O}$ gas mixture might suppress focal autoregulation in the cortex despite the lack of fall in arterial blood pressure.

In our study, we measured $\mathrm{rCBV}$ and obtained image changes under six different conditions. Of all the conditions tested, the response to bicuculline was maximal under $1.5 \%$ isoflurane in air. Therefore, we propose that this condition is the most suitable for fMRI using isoflurane. As an additional check, we plan to further evaluate fMRI over a longer measurement period using the same conditions.

\section{Conclusion}

Our study showed that the transient changes in rCBV induced by pharmacological stimulation with bicuculline under six different conditions of anesthesia and hypoxia can be observed with high spatial resolution fMRI. fMRI can therefore be performed under general anesthesia such as isoflurane, in spontaneously breathing, well-anesthetized animals. Under these conditions, the optimal reaction to bicuculline was observed under $1.5 \%$ isoflurane mixed in $40 \% \mathrm{O}_{2}$ and $60 \% \mathrm{~N}_{2}$. The depth of anesthesia and physiological conditions strongly affect the intensity and localization of the fMRI response. Our results imply that the rCBV changes under this level of isoflurane anesthesia with body temperature maintained at $37.5^{\circ} \mathrm{C}$ might be suitable for fMRI studies. 


\section{References}

1 Duffau H, Capelle L, Denvil D, Sichez N, Gatignol P, Taillandier L, Lopes M, Mitchell MC, Roche S, Muller JC, Bitar A, Sichez JP, van Effenterre R: Usefulness of intraoperative electrical subcortical mapping during surgery for low-grade gliomas located within eloquent brain regions: Functional results in a consecutive series of 103 patients. J Neurosurg 2003; 98:764-778.

2 Ogawa S, Lee TM, Nayak AS, Glynn P: Oxygenation-sensitive contrast in magnetic resonance image of rodent brain at high magnetic fields. Magn Reson Med 1990;14:68-78.

3 Detre JA, Leigh JS, Williams DS, Koretsky AP: Perfusion imaging. Magn Reson Med 1992;23: 37-45.

4 Reese T, Bjelke B, Porszasz R, Baumann D, Bochelen D, Sauter A, Rudin M: Regional brain activation by bicuculline visualized by functional magnetic resonance imaging. Timeresolved assessment of bicuculline-induced changes in local cerebral blood volume using an intravascular contrast agent. NMR Biomed 2000;13:43-49.

5 Mandeville JB, Marota JJ, Kosofsky BE, Keltner JR, Weissleder R, Rosen BR, Weisskoff $\mathrm{RM}$ : Dynamic functional imaging of relative cerebral blood volume during rat forepaw stimulation. Magn Reson Med 1998;39:615-624.

6 Krnjevic K: Glutamate and $\gamma$-aminobutyric acid in brain. Nature 1970;228:119-124.

7 Meldrum BS, Nilsson B: Cerebral blood flow and metabolic rate early and late in prolonged epileptic seizures induced in rats by bicuculline. Brain 1976;99:523-542.
8 Winn HR, Welsh JE, Rubio R, Berne RM: Changes in brain adenosine during bicucullineinduced seizures in rats. Effects of hypoxia and altered systemic blood pressure. Circ Res 1980; 47:568-577.

9 Rehncrona S, Siesjo BK, Westerberg E: Adenosine and cyclic AMP in cerebral cortex of rats in hypoxia, status epilepticus and hypercapnia. Acta Physiol Scand 1978;104:453-463.

10 Leniger-Follert E: Mechanisms of regulation of cerebral microflow during bicuculline-induced seizures in anaesthetized cats. J Cereb Blood Flow Metab 1984;4:150-165.

11 Wible JH Jr, Luft FC, DiMicco JA: Hypothalamic GABA suppresses sympathetic outflow to the cardiovascular system. Am J Physiol 1988;254:680-687.

12 Blennow G, Nilsson B, Siesjo BK: Influence of reduced oxygen availability on cerebral metabolic changes during bicuculline-induced seizures in rats. J Cereb Blood Flow Metab 1985; 5:439-445.

13 Astrup J, Blennow G, Nilsson B: Effects of reduced cerebral blood flow upon EEG pattern, cerebral extracellular potassium, and energy metabolism in the rat cortex during bicuculline-induced seizures. Brain Res 1979;177: 115-126.

14 Kreisman NR, Hodin RA, Rosenthal M, Sick $\mathrm{TJ}$ : Role of pulmonary edema in phasic changes of cerebral oxygenation during serial seizures. Brain Res 1987;417:335-342.
15 Kloiber O, Bockhorst K, Hoehn-Berlage M, Hossmann KA: Effect of hypoxia on bicuculline seizures of rat: NMR spectroscopy and bioluminescence imaging. NMR Biomed 1993;6: 333-338.

16 Antkowiak B, Helfrich-Forster C: Effects of small concentrations of volatile anesthetics on action potential firing of neocortical neurons in vitro. Anesthesiology 1998;88:1592-1605.

17 Caspers H, Speckmann EJ: Cerebral $\mathrm{pO}_{2}$, $\mathrm{pCO}_{2}$ and $\mathrm{pH}$ : Changes during convulsive activity and their significance for spontaneous arrest of seizures. Epilepsia 1972;13:699-725.

18 Siesjo BK, von Hanwehr R, Nergelius G, Nevander $G$, Ingvar $M$ : Extra- and intracellular $\mathrm{pH}$ in the brain during seizures and in the recovery period following the arrest of seizure activity. J Cereb Blood Flow Metab 1985;5:47_ 57.

19 Blennow G, Folbergrova J, Nilsson B, Siesjo BK: Effects of bicuculline-induced seizures on cerebral metabolism and circulation of rats rendered hypoglycemic by starvation. Ann Neurol 1979;5:139-151.

20 Sugaya T, Kitani Y: Nitrous oxide attenuates the protective effect of isoflurane on microtubule-associated protein 2 degradation during forebrain ischemia in the rat. Brain Res Bull 1997;44:307-309.

21 Pelligrino DA, Miletich DJ, Hoffman WE, Albrecht RF: Nitrous oxide markedly increases cerebral cortical metabolic rate and blood flow in the goat. Anesthesiology 1984;60:405-412. 